\title{
Descubrimiento de América y del hambre y las enfermedades en el Nuevo Mundo
}

Jaime Alberto López Nuila

Toda la información que se conoce sobre el Descubrimiento de América está contenida en las llamadas Crónicas, que historiadores al servicio de la Corona española realizaban sobre el magno acontecimiento. Hay también información conocida en la obra completa sobre el Descubrimiento redactada y responsabilizada por el fray Bartolomé de las Casas. Este era, parece, el responsable del relato que interesaba al Gobierno de España y también a la Iglesia católica, en un momento de la historia en el que el poder de la Iglesia abarcaba aspectos relacionados con la conciencia del hombre, pero que también comprendía otros intereses que tenían carácter material.

Además del representante del clero - De las Casas, el más conocido entre muchos y quizá el más respetado- había en las expediciones al Nuevo Mundo los cronistas que actuaban para el servicio de la Corona. Entre ellos Gonzalo Fernández de Oviedo y Valdez. Este resulta ser, por lo menos, el que se revela como responsable de gran cantidad de información, mucha de ella de carácter trascendental para el acto mismo del descubrimiento, como del propio país descubierto. Y más importante todavía, del propio pueblo que habita en la llamada isla La Española.

Este cronista, embarcado en verdad como veedor de los recursos auríferos en el Nuevo Mundo - una especie de visor o testigo y tal vez ahora un auditor del monarca - visita al menos en una oportunidad el nuevo continente y se convierte, por obra de sus informes, en la fuente que certifica el primer acontecimiento en La Española, que produce en aquella época consecuencias para la misma empresa militar del Descubrimiento y Conquista, y que influye, así mismo, en la historia misma del pueblo indígena y de aquella isla, al hacerla teatro y elenco de la llamada primera hambruna en la América India. 
Todo apunta a que Gonzalo de Oviedo, por no haber sido testigo presencial de algún suceso, difícil o trágico ocurrido en la primera ciudad fundada en el Nuevo Mundo, La Isabella, en la isla bautizada por Colón como La Española en la costa norte (hoy costa atlántica) donde se ubica la República Dominicana, sostuvo y afirmó los hechos que se ofrecían como el primer acontecimiento que se registra en las crónicas, y que se narra como una situación de hambre catastrófica, una especie de plaga que produjo centenares o miles de muertos entre nativos y españoles, de forma que el primer asentamiento del descubridor y conquistador en América termina en desastre y abandono.

Las informaciones de Oviedo son, por lo menos, contradictorias, desde el momento en que sus mismas crónicas detallan que aquel mundo recién descubierto es - según sus propias palabras - casi el mundo de la abundancia, por la enorme cantidad de recursos de la tierra, del aire y del mar que encuentran en esa primera experiencia. El veedor no encontró en La Española - eso es cierto - nada que tuviese relación con su cargo de Veedor de las Fundiciones de Oro, puesto que incluso en este encargo era para posibles hallazgos, que sí se dieron en tierra firme, más no en aquel territorio insular. No encontrará oro, talvez, pero lo que si existía, y en abundancia, eran recursos para alimentar no solo al pueblo indígena, que ya la habitaba desde lejanos tiempos, sino también a los recién llegados.

Es precisamente la obra de Oviedo, referida a la descripción de la naturaleza de las Indias, lo que le ha producido cierta fama en la obra del Descubrimiento y la Conquista o colonización. Su obra mas reconocida es su Historia Natural y General de las Indias. Antes había escrito Sumario sobre la Natural Historia de las Indias; ambas están basadas en la impresión de la reconocida existencia de enormes y ricos recursos naturales del Nuevo Mundo. Es cierto que su última experiencia le permite vivir en sus funciones de alcalde de la Fortaleza de Santo Domingo, desde 1535 hasta 1545, lo que significa diez años de su vida transcurridos justamente en La Española.

Como sea, la verdad es que existen datos abundantes que indican que Oviedo fue, cuando menos, superficial en sus comentarios y detalles sobre lo ocurrido en 1493 en La Isabella. En La Historia de las Indias, De las Casas no es coincidente con Oviedo respecto a la desaparición del primer asentamiento en América. Se detallan actos de hostilidad por parte de los naturales debido a los inconvenientes sufridos y por el carácter del asentamiento referido; pero, sobre todo, porque sin ninguna duda el consumo de las vituallas traídas en el 
primer viaje por los conquistadores debieron ser insuficientes, consumiéndolas demasiado rápido por los recién llegados al Nuevo Mundo.

De lo narrado por los diferentes cronistas de las Indias, consta que en el primer reconocimiento de la isla que hizo Colón mismo $-\mathrm{y}$ así lo atestigua él ante la Corona- quedó sobrecogido por el espectáculo de la abundancia. Hay rastros históricos en los Archivos de Indias en los que aparecen testimonios diversos sobre este tema, y que hacen una descripción única y uniforme de lo que ven sus ojos. Así, Luis de Santángel, al dar cuenta de su hazaña descubridora dice:

En este tiempo anduve así por aquellos árboles, que era la cosa mas fermosa de ver que otra se haya visto, leyendo tanta verdura en tanto grado como en el mes de mayo en el de Andalucía. Y los árboles todos tan disformes de los nuestros como el día de la noche. Y después hay árboles de mil maneras y todos de su manera fruto, y todos huelen que es maravilla.

Lo que Luis de Santángel narra resulta ser, comparándolo con el informe supuesto de Oviedo y su "situación de hambre catastrófica, especie de plaga que llenó de cadáveres pestilentes los parajes antes lisonjeros y los aires antes perfumados" - para usar los términos de su informe anterior - justamente como el día y la noche. Se decía de la isla en aquel tiempo que. "en esta Isla había tanta espesura de árboles no conocidos a nadie que era para espantar, dellos con fruto dellos con flor, aunque todo era verde”. Es decir, que la visión del Nuevo Mundo para aquellos hombres no era, para nada, la idea de un paraje desierto, desolado, yermo o infértil, sino todo lo contrario. Lo que hace que la hambruna que describe Oviedo sea más el producto de la fantasía que de una experiencia cierta y efectivamente vivida.

Gonzalo Fernández de Oviedo - es cierto - describió a los indígenas sin antipatía y sin idealizarlos. También es cierto que reprochó a los conquistadores, su innecesaria crueldad, y, además, como observador de la naturaleza fue en sus juicios sagaz y penetrante. También se le reconoce que en sus narraciones e informes reseña, de preferencia, los hechos que conoce por experiencia directa. El problema con su informe sobre el hambre y la mortandad en La Isabella resulta, con todo, increíble, por ser contradictoria. Primero, con sus propios relatos sobre la naturaleza y la topografía de la isla La Española, en el contexto total de sus informes, lo mismo que con los relatos de cronistas 
que le precedieron o que le sucedieron, después de 1545, con su regreso a Valladolid, en donde muere. También lo contradice en forma total la descripción mas detallada que sobre la isla hace luego de su descubrimiento, como lo hemos comprobado con lo dicho por Luis de Santángel.

Pero ¿de dónde obtiene Oviedo la certeza y el conocimiento que le lleva a decir que el hambre azotó a los españoles tanto como a los indios?, al extremo de que los cadáveres se encontraban por todas partes y que "el hedor era muy grande é pestifero". "En consecuencia, las dolencias que acudieron sobre los cristianos fueron muchas allende el hambre”. Quiere decir que, más allá del hambre, o justo a causa del hambre, las dolencias que sufren los cristianos, es decir, los españoles, fueron muchas. ¿Por qué motivo pudo informar de una hambruna en los términos catastróficos en que se menciona?

La verdad es que nadie más que el propio Oviedo podía dar un testimonio digno de crédito sobre las características de la isla recién descubierta, porque era - como lo mencionamos al principio - cronista oficial de la Corona y, además y sobre todo, notario público. Dador de fe sobre lo por él comprobado. Oviedo se encargó de hacer justamente un recuento minucioso de los árboles, las plantas, las hierbas, indicando cuáles tenían cualidades curativas y cuáles eran comestibles. Oviedo mismo - naturalista por vocación y cronista por oficio- descubre el níspero, y al describirlo exclama: "Esta fruta es la mejor de todas las frutas, a mi juicio e de otros muchos que suelen decir lo mismo, porque es del mas lindo sabor é gusto que se puede pensar, e yo no hallo cosa a que se pueda comparar ni que se le iguale".

Al descubrir la piña, dice Oviedo:

Este es uno de los mas fermosos frutos que yo he visto en todo lo que del mundo he andado. No pienso que en el mundo la haya que la iguale en estas cosas que agora diré, las cuales son hermosura de vista, suavidad de olor, gusto de excelente sabor, así que de cinco sentidos corporales, los tres que se pueden aplicar a las frutas, y aún el cuarto, que es palpar, en excelencia participa de estas cuatro cosas.

Todo lo que de exageración pueda estimarse en la contemplación que hace Oviedo de la piña, se disculpa si reparamos que tiene total y absoluta razón cuando se refiere al olor, al sabor, a la hermosura del fruto a la vista, puesto que tales atributos existen. Hasta la descripción del efecto al tacto que hace de ese un especial fruto, que no se aparta del ojo contemplativo que ve con 
carácter singular la forma de la piña y su revestimiento, o superficie, tan particular.

¿Cómo puede explicarse, entonces, su versión de hambre y plaga que sostiene se desata de repente en La Isabella? Cualquiera que sea la razón, lo cierto es que tanto los españoles que llegaron en sus carabelas a la isla como los pobladores nativos que ya la habitaban encontraban y disponían de todo lo que necesitaban para su alimentación; y se ha comprobado que los recursos nutritivos propios de la isla a la llegada de los españoles fueron el resultado final de un largo proceso de contribución, mediante el trasplante de innumerables ejemplos del reino vegetal, la mayoría con características y propiedades alimenticias propias de tierra firme, de donde posiblemente llegaron los indios que Colón encontró en La Española cuando se produce el descubrimiento.

La verdad es que la tal hambruna hasta los propios y reales acontecimientos se encargan de desmentir, aún cuando durante los primeros seis meses después del descubrimiento que, es de temer, fueron o debieron ser los más duros, por aquello del proceso de adaptación después del conocimiento de aquel Nuevo Mundo, y durante los que talvez sí sea cierto que se produjo desabastecimiento porque se agotaron las provisiones originarias. En La Española se pudo disponer de varias y muy calificadas fuentes de alimentación: lo que se conservó de las provisiones primeras; lo que vino después; y antes de esos seis meses, lo procedente de Sevilla como reaprovisionamiento; y finalmente, lo que se podía conseguir en la isla, que nunca fue poco.

La dieta de los españoles en esos meses pudo haber estado compuesta por el filete de jutía acompañado de casabe, que sustituía al pan de trigo español, puesto que el casabe era justamente el pan de los pueblos originarios. También pudo estar presente la iguana, que era junto al casabe el plato preferido de los pueblos originarios de La Española. Estos limpiaban la iguana, la enrollaban y la ponían en una cazuela del mismo tamaño que el animal, luego se hervía a fuego lento sobre candentes palos. Se aprovechaban desde entonces, también, los huevos de la iguana, que constituían un plato adicional al principal, que era su carne. Para adaptarlos al gusto del conquistador, tanto la jutía como la iguana debieron ser condimentadas con ajíes picantes, por ejemplo, o por otros productos de la península, que hicieron que en su momento, - hablando justamente de la gastronomía en la isla - el comentarista Xavier Domingo dijese un día: “Acabamos de entrar en las nuevas tierras y aún tenemos en el paladar capas y capas de gusto de la vieja despensa”, haciendo 
referencia justamente al menú europeo que, sin duda, debía estar presente en aquellos primeros tiempos en su mente, al adaptar los recursos propios a la cocina indígena.

Todo lo referido convierte a la crónica de Oviedo sobre la hambruna en La Isabella en algo así como una verdadera fantasía, producto de su imaginación, que, contrasta felizmente con el contenido de toda la crónica que se produce sobre la colonización y conquista del Nuevo Mundo. Incluso es de aceptación general, y además con carácter histórico, que la causa del abandono por los españoles del primer asentamiento en la isla La Española, se debió a la resistencia de los pueblos originarios, por lo menos al principio; a la nueva condición de dependencia del recién llegado, vínculos que por la brutalidad y la crueldad del trato hacia ellos los convertirían en esclavos. Pues bien, cuando el aborigen se percata de su nueva condición de sujeción y dependencia toma la decisión de resistirse, huyendo al menos del contacto con ese hombre "superior" a él, y privándole con ello - al español - de aquel sirviente que le es tan indispensable.

Se ha sostenido incluso que hubo algún natural de la isla que se rebeló, en los términos de combatir al que para él había invadido su tierra, y que producto de esas acciones se llegó inclusive a la quema de los asentamientos que en forma por demás precaria habían construido los españoles en La Isabella; y que, finalmente, más por esa conducta, que solo fueron gérmenes de levantamiento y oposición, los españoles toman la decisión de abandonar aquel asentamiento.

Sin embargo, la verdad sobre las reales razones del abandono del asentamiento en La Isabella se conocen luego con las crónicas y los testimonios de otros personajes como De las Casas, quien hace los primeros cargos en contra de los españoles porque, dice, arrebataban a los indios su comida, y además sus mujeres. Hubo algunos que sobre este tema del abuso del europeo en contra de los naturales y el despojo que les hacen de sus propias mujeres, tratando de justificarlo, dicen que, primero, tenía que darse esa conducta porque no podía ser de otra manera; y segundo, que las mismas mujeres naturales se entregaban al europeo de su propio gusto.

Esta faceta de la conducta del español en las nuevas tierras deja todavía con un velo de misterio la razón de las denuncias de Oviedo sobre la naturaleza catastrófica del hambre que obliga a abandonar La Isabella. Hoy se sabe que 
esa conducta de abuso y despojo a los pueblos originarios no solo de su tierra y alimento, sino también de sus propias mujeres, trae aparejada la verdadera catástrofe humana, sobre todo para el indígena. La unión del español con la india trae algo más que una unión carnal. Lo denunció en el siglo XVIII el párroco Antonio Sánchez Valverde, afirmando que el hambre de que hablaba Oviedo fue confundida con una epidemia que estalló de manera inesperada, y que su causa era el encuentro de un organismo indefenso como el de los pueblos originarios con los gérmenes desconocidos que llegaban de Europa. En verdad esa epidemia presentó tal virulencia que, conocida ya en Europa con diferentes nombres, terminó siendo identificada como sífilis. Oviedo, talvez por patriotismo, quiso fincar el abandono en una supuesta hambruna, pero fue la promiscuidad del europeo la que causó, a la larga, una cadena de infortunios que solo terminan, especialmente en La Española, en la absoluta y total exterminación de los pueblos originarios.

Este ser indefenso fue la víctima propiciatoria que fue conducida, en aras del desarrollo de la humanidad y en nombre del descubrimiento, a su propia extinción. Llegados a La Española en sus frágiles cayucos, habían poblado densamente la isla, y migrado tras sucesivas y continuas avanzadas por mar en el Caribe, a veces por su propia seguridad hacia las islas vecinas. Pero seguros como estaban en su hábitat, debieron primero soportar la llegada de otros pueblos originarios más violentos y aguerridos como los caribes, de los que se afirma que también habrían sido caníbales, y que los habían obligado a huir a otras islas.

Luego fueron los europeos, entre conquistadores y filibusteros, que llegaron repletos e hinchados de ambición, de poder y de riquezas. Más tarde serán los provenientes de África los que llegarían, cuando ya los naturales de la isla están extintos o por extinguirse... Todo lo perdieron al final aquellos pueblos inocentes, que desaparecieron así totalmente, al menos en la isla, de la faz de la Tierra. La versión del cronista español sirve así de disfraz para ocultar el primer acto de exterminación masiva que se da en nombre del progreso.

\section{Referentes bibliográficos}

De Las Casas, Fray Bartolomé, Historia de las Indias. Sociedad Dominicana de Bibliófilos Inc. Tomo I. República Dominicana. 1978.

Diccionario Enciclopédico Quillet, Editora, Tomo IV. España. Cumbres, S.A. 8. ${ }^{a}$ Edición. 1978. 
Mir, Pedro, Historia del hambre. Sus orígenes en la República Dominicana. Editora Corripio. 1987.

Moya Pons, Frank, Manual de historia dominicana. 6. ${ }^{a}$ Edición, Santa Domingo. 1960.

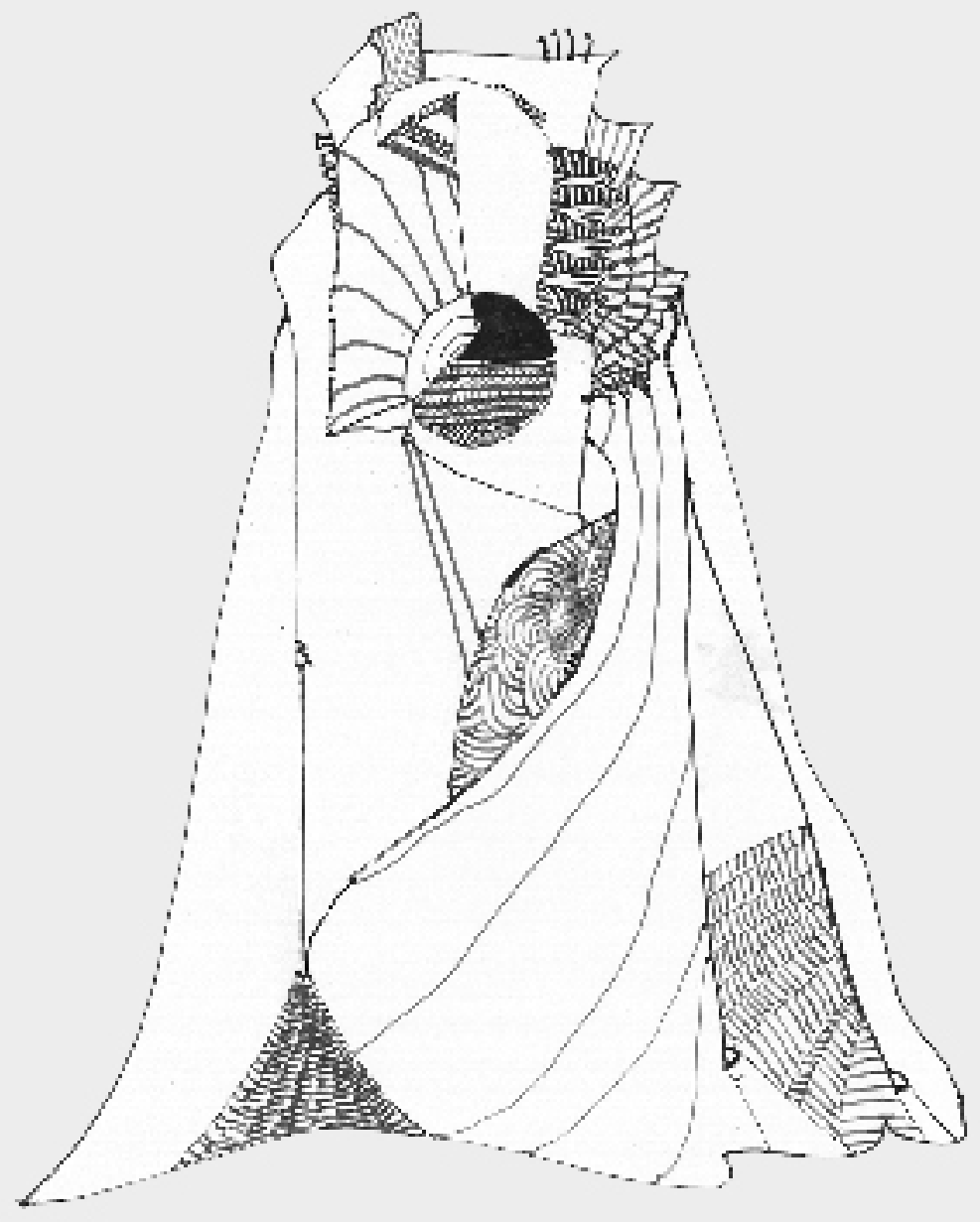

